\title{
Schopenhauer e Augusto dos Anjos: sobre a arte poética
}

Schopenhauer and Augusto dos Anjos: about the poetic art

\author{
Vilmar Debona \\ Doutor em Filosofia pela USP \\ Professor do Programa de Pós-Graduação em Filosofia e \\ do Departamento de Educação e Sociedade da UFRRJ \\ E-mail: debonavilmar@gmail.com
}

Resumo: $O$ presente artigo destaca alguns aspectos da concepção de poesia em Schopenhauer com o objetivo de problematizar possíveis aproximações e distanciamentos entre a poesia lírica de Augusto dos Anjos e as características e papeis que Schopenhauer atribui à arte poética e ao poeta. As possíveis convergências e divergências entre o filósofo alemão e o "poeta maldito" são abordadas por meio de uma análise da concepção schopenhaueriana de exposição (Darstellung) e não por meio das visões de mundo em geral do filósofo e do poeta, visões que só poderiam ser concebidas como semelhantes ou divergentes de forma conjectural.

Palavras-chave: Schopenhauer; Augusto dos Anjos; Exposição poética.
Abstract: This paper highlights some aspects of the conception of poetry in Schopenhauer in order to discuss possible similarities and differences between the poetry of Augusto dos Anjos and the characteristics and roles that Schopenhauer attaches to the art of poetry and to the poet. The possibles convergences and divergences between the german philosopher and the "accursed poet" are addressed by means of a analysis of Schopenhauer's concept of exposure (Darstellung) and not by means of the worldviews in general of the philosopher and of the poet, that only may be taken as similar or divergent in conjectural sense.

Keywords: Schopenhauer; Augusto dos Anjos; Poetic exposure. 
No alheamento da obscura forma humana, De que, pensando, me desencarcero, Foi que eu, num grito de emoção, sincero, Encontrei, afinal, o Meu Nirvana!

Nessa manumissão schopenhaueriana, Onde a vida do humano aspecto fero Se desarraiga, eu, feito força, impero $\mathrm{Na}$ imanência da Ideia Soberana!

Destruída a sensação que oriunda fora Do tacto - ínfima antena aferidora Destas tegumentárias mãos plebeias -

Gozo o prazer, que os anos não carcomem, De haver trocado a minha forma de homem Pela imortalidade das Ideias ${ }^{1}$.

Meu Nirvana, único poema de Augusto dos Anjos em que
encontramos uma referência direta ao pensamento de
Schopenhauer, foi publicado na Gazeta de Leopoldina, no dia 14 de novembro de 1914, dois dias após a morte do poeta, ocorrida na mesma cidade que dá título ao jornal, no interior de Minas Gerais. Um de seus últimos trabalhos, o poema fora ditado a um amigo quando o autor já pressentia "o fim da orgânica batalha"2, debilitado em seu leito derradeiro pela pneumonia que o matara aos 31 anos de idade. $E$, no entanto, não é difícil perceber como este poema possui o mesmo fundo temático de muitos outros, talvez da maioria deles. Para ficarmos com um exemplo de como a temática do (talvez schopenhaueriano) O Meu Nirvana encontra-se proliferada por toda a obra de Augusto dos Anjos, notemos que o encontro com o Nirvana ali narrado tem como condição o desencarceramento da "obscura forma humana", assim como o prazer por ter trocado a "forma de homem" "pela imortalidade das Ideias" (prazer que, sublinhe-se, não é carcomido pelos anos) só é possível após a destruição da sensação oriunda do tacto. Trata-se de um

\footnotetext{
1 ANJOS, A. Eu e outras poesias, p. 126, grifo meu.

2 Referência ao poema Apóstrofe à carne, no qual Augusto dos Anjos canta a proximidade de sua própria morte com os seguintes versos: Quando eu pego nas carnes do meu rosto / Pressinto o fim da orgânica batalha: / - Olhos que o húmus necrófago estracalha, / Diafragmas, decompondo-se, ao sol posto... / E o Homem - negro heteróclito composto, / Onde a alva flama psíquica trabalha. / Desagrega-se e deixa na mortalha / O tato, a vista, o ouvido, o olfato e o gosto! [...] (ANJOS, A. Eu e outras poesias, p. 57-58).
} 
assunto muito próximo do abordado no conhecido Monólogo de uma sombra (que o poeta escolheu para abrir aquela que seria sua única obra, o $E u$ ), onde vemos a "sombra" iniciar seu monólogo narrando ter vindo "de outras eras /, Do cosmopolitismo das moneras...", "da escuridão do cósmico segredo", "da substância de todas as substâncias"3; sombra esta que encontra "a prova de que a dor como um dartro se renova / Quando o prazer barbaramente a ataca...", e que admite, ao final, que "Somente a Arte, esculpindo a humana mágoa / Abranda as rochas rígidas, torna água / Todo o fogo telúrico profundo / E reduz [...] à condição de uma planície alegre / A aspereza orográfica do mundo!"4.

Se a "Arte" que, em Monólogo de uma sombra, transforma a aspereza do mundo numa "planície alegre" possui ou não o mesmo teor schopenhaueriano de $O$ Meu Nirvana, onde a "manumissão schopenhaueriana" alforria o homem de sua miséria encarceradora e Ihe fornece acesso à imortalidade das Ideias, sempre será sedutor associar versos como os citados acima a concepções da metafísica de Schopenhauer e, em especial, à sua metafísica do belo. Tal metafísica, em sua imanência, leva consigo noções caras ao vocabulário augustiano: desejo, volição, dor, sofrimento, corpo, organismo humano, universo, cosmos, forma ilusória, Ideia, morte, nada etc compõem o reportório tanto do poeta quanto do filósofo. Se aceitas como similares, estas noções oferecem uma gama de possibilidades de estudos comparativos entre os dois pensamentos, o que já se fez (ou se faz) no Brasil, ainda que não com afinco em Filosofia, mas notadamente nos âmbitos da Crítica da arte, das Letras e da Literatura. Estudos esparsos já se dedicaram a mostrar que tanto Schopenhauer quanto Augusto dos Anjos defendem que a dor é um importante constituinte do mundo, sendo perene; que a natureza humana é desproposital e malévola; que é pelo amor, pela satisfação de desejos, pelo sexo e perpetuação da espécie que se prolonga o sofrimento humano no mundo; que salvação e bemaventurança só são possíveis por meio do ascetismo, do encontro com o nada ${ }^{5}$. Enfim, que Augusto dos Anjos, por partilhar de muitas noções comuns ao chamado pessimismo metafísico de Schopenhauer, poderia ser considerado um schopenhaueriano, constatação que ganha força pelo fato de o poeta ter dado preferência ao universo em decomposição, em seu melancólico e desesperado 
"evangelho da podridão".

No entanto, até onde essa convicção poderia ser assegurada? Ela resistiria ou poderia conviver, p. ex., com as recorrentes menções do poeta a pensadores e cientistas darwinistas e positivistas, como a Ernst Haeckel e a Herbert Spencer? Seria Augusto dos Anjos um poeta schopenhaueriano, se sua poesia, mesmo difícil de ser classificada, é tida como poesia científica ${ }^{6}$, impregnada que é de termos e noções da biologia, da química e da medicina ${ }^{7}$ ? Mais ainda: o rebuscamento com termos técnicos e abstrações científico-filosóficas, capazes de impor ao leitor menos erudito uma recorrência constante a dicionários para poder intuir a mensagem de seus versos, ainda permitiriam tomar essa poesia como schopenhaueriana, sendo Schopenhauer o mais ferrenho defensor da recusa do conceito em artes e da incapacidade conceitual científica de transmitir objetivamente as Ideias, arquétipos do mundo?

O propósito do presente artigo não é o de indicar possíveis aproximações entre o filósofo alemão e o poeta brasileiro por meio de noções que supostamente Ihe foram comuns ou por meio de comparações entre suas cosmovisões. Nem é, também, o de oferecer um estudo historiográfico sobre as fontes schopenhauerianas de Augusto dos Anjos (como, p. ex., a quais obras do pensador o poeta teve acesso, se sua leitura era ou não recorrente etc). Ao invés disso, meu propósito é, num primeiro momento, o de frisar alguns aspectos da concepção de poesia em Schopenhauer afim de, num segundo momento, indicar aspectos de possíveis aproximações e de possíveis distanciamentos entre a natureza da poesia lírica augustiana e as características e papeis que Schopenhauer atribui à arte poética e ao poeta. Dessa forma, poderemos chegar a possíveis respostas para as questões acima elaboradas. Meu objetivo - o de problematizar a poesia de Augusto dos Anjos frente à metafísica do belo de Schopenhauer segundo sua forma e sua expressividade e não segundo o seu conteúdo - encontra uma justificativa na afirmação de um dos maiores críticos brasileiros de arte, Alfredo Bosi, que, ao comentar justamente a obra do poeta do Eu, afirma:

\footnotetext{
6 A poesia científica, no Brasil, teve como grandes precursores Sílvio Romero, discípulo de Tobias Barreto, e José Isidoro Martins Júnior, no final do século XIX e início do século XX. Tratou-se de uma corrente que se propôs, em linhas gerais, a substituir o romantismo. Isso muito se deve à influência inconteste que Augusto dos Anjos recebeu do cientificismo da Escola do Recife, onde estudou.

7 O que levou, inclusive, o Eu a ser "incorporado à biblioteca da Faculdade de Medicina do Rio de Janeiro" (PRADO, A. A. Um fantasma na noite dos vencidos, p. 43)
} 
A crítica, depois de interpretar a cosmovisão de um artista, não lhe deve pedir senão uma virtude: a expressividade. $\mathrm{E}$ toda expressividade leva, quando repuxada até às raízes, à invenção, à construção, à formalização. Nessa perspectiva, é que as palavras serão ou não necessárias esteticamente ${ }^{8}$.

Frente às muitas possibilidades de suposições que aproximam o poeta do filósofo, mas que contrastam sobremaneira com a carência de referências diretas do paraibano ao pensador alemão, a ideia de interpretar cosmovisão do poeta frente ao pensamento schopenhaueriano mediante conceitos e visões de mundo, embora mais sedutora e fácil, pode resultar mais comprometedora. Dessa forma, questões de exposição e de expressividade com suas justificações (razões) apresentam-se como método mais pertinente - por requerer menos suposições - afim de ponderarmos possíveis recepções do pensamento schopenhaueriano em terras tupiniquins mediante este peculiar acontecimento da literatura brasileira, que é a poesia necrófaga do "poeta maldito".

Em O mundo como vontade e como representação ( $(50)$, Schopenhauer justifica em que medida se daria a sua recusa do conceito em artes por meio de uma explicação sobre a recusa da alegoria nas artes plásticas. É que, segundo ele, ao enviar a algo outro em relação àquilo que expõe (que, por isso, se apresenta como abstração), a alegoria seria um obstáculo para a exposição ou transmissão da Ideia de forma intuitiva e límpida, tarefa genuína da obra de arte. Numa pintura, p. ex., a alegoria impediria tal tarefa por forçar a procura pelo significado da obra de arte num âmbito alheio à exposição da pintura. No entanto, Schopenhauer frisa como as coisas se dão numa relação inversa quando se trata da poesia:

A alegoria tem com a poesia uma relação completamente diferente da que tem com a arte plástica: se nesta é repreensível, naquela é admissível e mesmo bastante útil. Pois na arte plástica a alegoria leva do intuitivo dado, justamente o objeto de toda arte, para os pensamentos abstratos; na poesia a relação é inversa: aqui o que é dado imediatamente por palavras é o conceito, e o próximo passo é sempre ir deste ao intuitivo, cuja exposição tem de ser sempre

8 BOSI, A. História concisa da literatura brasileira, p. 309, grifo do autor. 
executada pela fantasia do ouvinte. Se na arte plástica é-se conduzido de algo dado imediatamente a algo outro, este tem de ser sempre o conceito, porque aqui só o abstrato não pode ser dado imediatamente; porém, um conceito nunca pode ser a origem, e sua comunicação nunca pode ser o fim de uma obra de arte. Na poesia, ao contrário, o conceito é o material, o dado imediatamente, e que por conseguinte pode ser sem problemas abandonado para se invocar algo intuitivo por completo diferente dele e no qual o alvo propriamente dito é atingido. No desenvolvimento de uma poesia muitos conceitos ou pensamentos abstratos podem ser imprescindíveis e não são intuíveis em si mesmos e imediatamente: com isso são frequentemente trazidos à intuição mediante um exemplo particular subsumido a eles ${ }^{9}$.

Esta esclarecedora passagem de O mundo já nos possibilita ponderar - ou mesmo admitir - que a poesia de Augusto dos Anjos, ao menos em alguma medida e apesar de seu uso recorrente de termos e conceitos abstratos, ainda revelaria uma natureza supostamente schopenhaueriana. Porém, se Schopenhauer observa que, em poesia, um conceito pode ser abandonado, ao mesmo tempo em que muitos conceitos e pensamentos abstratos podem ser imprescindíveis, mesmo não sendo intuíveis de forma imediata, isso certamente não significa que o filósofo estava admitindo o uso predominante de termos e conceitos - ainda mais científicos - na poesia, mas apenas um uso moderado deles. Do mesmo modo, não é possível entender que Schopenhauer, a partir da referida admissão, estivesse aceitando a primazia do conceito abstrato ou a criação de neologismos com termos técnicos e científicos, como o faz constantemente o poeta brasileiro. Isso tudo continua se apresentando como estranho diante da concepção schopenhaueriana de arte poética. Afinal, para corroborar a passagem acima citada, o filósofo menciona a poesia de Cervantes - que com o verso "O sono é um manto que encobre por completo o ser humano" remetia-se ao conceito de sono como um momento de alívio de sofrimentos corporais e espirituais -, assim como a poesia de Kleist - que com "Aqueles cuja lâmpada noturna ilumina o globo terrestre" teria expressado belamente e de forma alegórica o pensamento de que os filósofos e investigadores iluminam o gênero humano. Mas, caso o tivesse conhecido, teria Schopenhauer citado o "poeta do hediondo" para ilustrar sua concepção de poesia a partir de versos como estes, de As cismas do destino?

9 SCHOPENHAUER, A. O mundo como vontade e como representação, § 50, p. 277 
A vingança dos mundos astronômicos

Enviava à terra extraordinária faca,

Posta em rija adesão de goma laca

Sobre os meus elementos anatômicos ${ }^{10}$.

Como já observou Fabiano Calixto, "toda esta quadra, encavalada em decassílabos e frases que beiram o hilário, para apenas falar do vento frio que o assola"11! Neste caso, não estariam o cientificismo dos vocábulos e as relações de tempo e espaço reveladas pelos adjetivos, impedindo que o poeta cumpra com seu papel, que é o de apreender a Ideia de humanidade em suas cadeias de ações, ou seja, a "objetidade adequada da coisa em si em seu grau mais elevado"12, que, neste caso, corresponderia ao próprio "eu augustiano" padecendo pelo frio?

O destaque das considerações de Schopenhauer sobre dois pontos específicos de sua teoria da arte poética poderá lançar luz à indagação. Ambos os pontos referem-se à questão da exposição (Darstellung), noção de fundamental importância na esfera da hierarquização das artes nessa filosofia, já que é também devido a questões próprias de exposição que uma arte pode ser considerada superior a outra ${ }^{13}$.

A primeira das referidas considerações diz respeito ao objeto e à tarefa do poeta. Notemos, p. ex., que se cabe ao poeta fazer o ouvinte intuir as Ideias da vida de forma objetiva e imediata, Schopenhauer define o objeto da arte poética como sendo, preferencialmente, "a manifestação da Ideia correspondente ao grau mais elevado de objetidade da vontade, a exposição dos seres humanos na série concatenada de seus esforços e ações" ${ }^{14}$. A poesia, nesse sentido, não exporia um objeto estático ou constante como fazem outras artes (notadamente a pintura e a escultura). O tema principal da arte poética seria o de apresentar "o ser humano [...] na medida em que se exprime não apenas mediante a simples figura e a expressão do rosto, mas por meio de uma cadeia de ações acompanhadas por pensamentos e afetos" $^{\prime \prime}$, condição que outorga superioridade à poesia no âmbito da hierarquia schopenhaueriana das artes. Nesse sentido, nas Preleções sobre a Metafísica do

10 ANJOS, A. Eu, p. 81.

11 CALIXTO, F. Introdução. In: ANJOS, A. Eu, p. 35

12 SCHOPENHAUER, A. O mundo como vontade e como representação, § 51, p. 283.

13 Como bem assinala Jair Barboza, "é só no âmbito da exposição que, de fato, é aceitável a superioridade de uma arte sobre outra, já que, quando da intuição estética, não se deve falar nisso, pois gênio e objeto da intuição são unos [...]" (BARBOZA, J. A metafísica do belo de Arthur Schopenhauer, p. 121)

14 SCHOPENHAUER, A. O mundo como vontade e como representação, § 51, p. 282.

15 Idem, ibidem. 
Belo, Schopenhauer salienta que se na poesia o comunicado imediatamente é somente o conceito abstrato, a tarefa tem de ser a de tornar as Ideias intuitivas ao expectador mediante os representantes dos referidos conceitos; o que, porém, "só é possível com a ajuda de sua [do ouvinte] própria fantasia" ${ }^{16}$. Como as palavras fazem efeito de forma imediata só sobre a razão, e não sobre a fantasia, a maior tarefa do poeta seria colocar tal fantasia em movimento de acordo com o fim correspondente e por meio de uma atuação indireta (no sentido de que é intermediada por conceitos), "de tal maneira que ela [a fantasia] crie no ouvinte as imagens nas quais ele conhece as Ideias"17.

A segunda consideração se remete aos meios dos quais o poeta disporia para executar seu ofício. Afinal, de que forma o poeta colocaria a fantasia do ouvinte em movimento? Schopenhauer indica que existiriam ao menos quatro meios para tanto: a) A composição de conceitos, que teria de se dar de forma que suas esferas se intersectem e nenhuma delas se restrinja a uma universalidade abstrata, mas que, ao invés do conceito, surja um seu representante intuitivo na fantasia do ouvinte. b) A construção intuitiva do exposto, com a qual o poeta teria que dar vivacidade à sua exposição e à sua expressão. "É a condução do conceito à intuição, que é alcançado pelo fato de o poeta não ser frio e vago ao narrar as ocorrências, mas sim colori-las, descrevendo-as de modo bastante determinado; portanto, ele abandona a universalidade do conceito abstrato e dirige-se para o inteiramente particular, 0 concreto [...]"18. c) A inerência e a propriedade da expressão, proprietas verborum, que diz respeito ao acerto na designação, mediante a qual o poeta precisa apreender o específico, "a essência íntima da coisa, exprimindo-a sem interferência do casual e do inessencial"19. d) A brevidade da expressão: "A expressão pormenorizada é sempre ruim: na poesia ela suprime todo efeito. A multidão de conceitos acompanhada por muitas palavras nos detém fixamente no mero pensamento e não permite alcançar a intuição"20.

16 SCHOPENHAUER, A. Metafísica do Belo, p. 193.

17 Idem, p. 193-194.

18 Idem, p. 195

19 Idem, p. 199

20 Idem, p. 201 
A poesia de Augusto dos Anjos, que desconcerta parâmetros de recepção por não se ajustar a nenhuma escola literária específica, conseguiria corresponder a essas exigências e pressupostos schopenhauerianos, sobretudo quanto à expressividade? Em que sentido? Não há forma mais pertinente para respondermos a essa questão do que considerarmos a marca predominante da exposição poética augustiana e suas características inerentes - o que nos permitiria constatar proximidades e distanciamentos em relação à concepção poética de Schopenhauer.

Uma primeira consideração precisa levar em conta as já mencionadas concepções schopenhauerianas sobre o objeto e a tarefa do poeta. Dado o material com o qual lida (a ideia de humanidade captável em cadeias de ações, pensamentos e afetos), o poeta teria que cumprir com as duas primeiras exigências (indicadas acima): compor os conceitos e dar a eles uma exposição intuitiva. É o que um poeta faz ao considerar que os exemplos particulares, as expressões figuradas, as metáforas e, conforme frisa o filósofo em outro momento, os epítetos e adjetivos ${ }^{21}$, quando apresentados ao lado de substantivos ou de conceitos, têm a força de compensar a frieza abstrata destes últimos e garantir ao leitor o acesso intuitivo à Ideia ali expressa. Ora, isso Augusto dos Anjos parece fazer, a seu modo, em quase todos os seus versos.

Tomemos emprestados alguns dos exemplos que Bosi selecionou: miséria anatômica, espécies sofredoras, desespero endêmico, mecânica nefasta, estranguladora lei, agregados perecíveis, apodrecimentos musculares, herança miserável de micróbios, cuspo afrodisíaco, intracefálica tortura, aspereza orográfica do mundo, fonemas acres, fotosferas mortas, sangue podre, anatômica desordem, energia abandonada ${ }^{22}$. Os substantivos, em sua maioria coloquiais e genéricos, fazem-se acompanhar por adjetivos que os colorem (mesmo que, no geral, com uma cor escura e fúnebre, é verdade) e os qualificam, dando-lhes formas específicas e concretas. Aqui parece importar pouco se o substantivo adjetivado remete-se a uma noção científica ou não: a combinação e a estrutura ainda nos permitiriam identificar traços de uma "poesia schopenhaueriana".

Porém, o que não soa schopenhaueriano nesse ponto é o fato de a carga cientificista, a bagagem abstrata e os termos técnicos de muitos versos não serem 
substantivos, mas justamente adjetivos, estes que deveriam ser os facilitadores do acesso intuitivo e o mais imediato possível à Ideia. Vejamos alguns exemplos: 0 calçamento sáxeo, de asfalto rijo, atro e vidrento; o trabalho genésico dos sexos; na ígnea crosta do Cruzeiro; na ascensão barométrica da calma; a expectoração pútrida e crassa / Dos brônquios pulmonares de uma raça; outras plantas dicotiledôneas. Ou ainda, para radicalizarmos, A híspida aresta sávea áspera e abrupta.

Perceberemos algo diferente, no entanto, se atentarmos para as possíveis correspondências de Augusto dos Anjos à necessidade destacada por Schopenhauer como o terceiro meio de o poeta colocar a fantasia do ouvinte em movimento, citado acima no item 3: a inerência e a propriedade da expressão, que se referem ao acerto na designação do que está sendo manifesto. Este é um ponto capaz de revelar um intento e uma característica peculiares do poeta do Eu que se coadunam de uma forma peculiar com a concepção schopenhaueriana de arte poética.

Para sabermos sobre o acerto ou não na designação, ou, nas palavras de Bosi, sobre a necessidade estética das palavras, é preciso estarmos de posse de uma visão geral e panorâmica das temáticas próprias do poeta. Como se sabe, Augusto dos Anjos cantou o horrível. É consenso por parte dos críticos a ideia de que sua poesia se apresentou muito impactante à sua época por ser "uma poética que se mostra como deboche à oficialidade dos donos do vernáculo e do 'sorriso da sociedade', tornando-se, deste modo, uma contrapoética"23; ou, nas palavras de Anatol Resenfeld, por ser uma poesia que projetou "o desafio do radicalmente feio à face do pacato burguês, desmascarando, pela deformação hedionda, a superfície harmônica e açucarada de um mundo intimamente podre" ${ }^{24}$. Para além do fator pessoal, ou seja, pela vida amarga que experimentou o poeta, que provavelmente foi decisivo na escolha de seus temas, é mister levar em conta que o lugar (social) de atuação de Augusto dos Anjos era o de uma burguesia estúpida, endinheirada e sorridente, disposta a ignorar as contradições históricas e sociais que as transformações do início do seu século $X X$ implicavam. A aspiração pela europeização do Rio de Janeiro (capital do Brasil) não importava para o preconceito,

23 CALIXTO, F. Introdução. In: ANJOS, A. Eu, p. 27

24 ROSENFELD, A. A costela de prata de Augusto dos Anjos. In: ROSENFELD, A. Texto/Contexto I, p. 265 
para a violência e para a exclusão que, por isso mesmo, tornavam tal sociedade um ambiente hostil e horroroso. Nesse sentido, nada mais pertinente para designar poeticamente uma sociedade assim putrefata e fétida que uma poesia putrefata. Os versos de Augusto dos Anjos operaram uma verdadeira necrópsia de uma sociedade que, por detrás da ideia do "bom gosto" entoado pela poesia de sua época, escondia, como já foi observado, "preconceito, redundância, tradicionalismo, autoritarismo, intolerância, conformismo etc" ${ }^{25}$. E a referida necrópsia se deixa vislumbrar quando lemos, p. ex., em Os doentes, que na "cidade dos lázaros" havia "um fígado doente que sangrava", um "eu" "coberto de desgraças", uma "boca junto de uma escarradeira, pintando o chão de coágulos sanguíneos"26; e ainda, no Amazonas, uma "carcaça esquecida de um selvagem" que "fedia, entregue a vísceras glutonas" 27 . Há, aqui, a mais cortante denúncia do sofrimento, da dor e do martírio étnico intrínsecos à colonização brasileira: "O gênio de Colombo manchou de opróbrios a alma do mazombo / Cuspiu na cova do marubixaba! / E o índio, por fim, adstrito à étnica escória / Recebeu, tendo o horror no rosto impresso / Esse achincalhamento do progresso / Que o anulava na crítica da História!"28. Como observou Calixto, "a podridão e a consciência da mesma (numa esfera existencial e política) é que fornece energia crítica a estes poemas. É uma leitura de mundo pela base, onde mais fede. Bate-se - e, acrescentemos, sangra-se - onde mais dói”29. Está claro, diante disso, o quão coerente e pertinente é a expressão augustiana, aquela proprietas verborum exigida por Schopenhauer, no que se refere à temática tratada pelo poeta.

Mas, e no que se refere ao cientificismo? Por mais paradoxal que pareça, Augusto dos Anjos, leitor do mundo pela chave da putrefação, constrói seus versos com o uso proposital do jargão científico. Porém, a poesia, que para ele não poderia não ser putrefata, teria de carregar, intrínseca a si, uma capacidade de libertação da condição que ela expressava, e esta capacidade viria, sobretudo, da inserção do neologismo, da palavra científica e do termo técnico no corpo "mofado". Nesse sentido, corpos em decomposição, recheados de vermes, que exalam o odor desagradável da existência e da civilização, são enunciados pela ou acompanhados

25 CALIXTO, F. Introdução. In: ANJOS, A. Eu, p. 28

26 ANJOS, A. Eu, p. 109-110.

27 Idem, p. 111.

28 Idem, p. 111-112.

29 CALIXTO, F. Introdução. In: ANJOS, A. Eu, p. 24 
pela terminologia científica - que, neste caso peculiar - não compromete a vivacidade da exposição, mas, ao contrário, pretende funcionar como antídoto libertário em relação ao que ela expressa. É o que parece estar presente nessa estrofe do Monólogo de uma sombra:

\author{
É uma trágica festa emocionante! \\ A bacteriologia inventariante \\ Toma conta do corpo que apodrece... \\ $E$ até os membros da família engulham, \\ Vendo as larvas malignas que se embrulham \\ No cadáver malsão, fazendo um $s^{30}$.
}

Trata-se de um duplo movimento: o cientificismo augustiano é um escárnio para a ciência e para as abstrações conceituais; e o "evangelho da podridão" é entoado pelo termo objetivo e não "contaminado" por tudo o que é "filho do carbono e do amoníaco", por tudo o que degenera e apodrece. Sobre esse ponto, Rosenfeld já se pronunciou de forma magistral:

\begin{abstract}
Augusto dos Anjos [...] buscava a palavra de dura e firme consistência, a palavra que não participasse da corrupção para que, deste modo, pudesse tanto melhor exprimir e superar as visões da podridão. [...] Exatos como fórmulas matemáticas, mas ao mesmo tempo de efeito encantatório como um ritual coreográfico, [os neologismos e os termos técnicos] tentam traduzir a 'imortalidade das ideias'. Cabe-lhes exprimir e promover a 'abolição', o desencarceramento da obscura forma humana, a libertação do apodrecimento, através de um artificialismo mental que não participa da decomposição de tudo que é orgânico. Não buscava esse 'minerálogo' da pureza virginal, ávido de 'rutilância fria' em meio dos pantanais, para quem 'Deus resplandecerá dentro da poeira / Como um gasofiláceo de diamante', não buscava Augusto dos Anjos no termo duro e artificial o que o vocábulo histórico, já amolecido pelo bafo de tantos pulmões doentes, não lhe poderia dar ${ }^{31}$ ?
\end{abstract}

Para Rosenfeld, sim, e é esse artifício que o crítico chama de "a costela de prata de Augusto dos Anjos", uma ferramenta inorgânica que o poeta inventara para interromper o encarceramento da poesia pela língua tradicional, orgânica e conformista. Afinal, se nessa "poesia do necrotério" até o ar se desagrega ${ }^{32}$, como não haveriam de se desintegrar também, para exprimi-la, a palavra e as metáforas

30 ANJOS, A. Eu, p. 65.

31 ROSENFELD, A. A costela de prata de Augusto dos Anjos. In: ROSENFELD, A. Texto/Contexto I, p. 268-269.

32 Cf. ANJOS, A. Os Doentes. In: Eu, p.111-112. 
tradicionais? Nesse sentido, não é a expressividade poética que se torna antila do termo técnico e da noção científica ${ }^{33}$, mas são o termo técnico e a noção científica que se tornam servos da exposição poética. A estranha pertinência do uso do termo técnico-científico para cantar o hediondo, o horrível e a podridão pode ser explicada também pelas palavras precisas de Bosi: "Em Augusto dos Anjos, o jargão científico e o termo técnico, tradicionalmente prosaicos, não devem ser abstraídos de um contexto que os exige e os justifica. Ao poeta do cosmos em dissolução, ao artista do mundo podre, fazia-se mister uma simbiose de termos que definissem toda a estrutura da vida (vocabulário físico, químico e biológico) e termos que exprimissem o asco e o horror ante essa mesma existência imersa no Mal"34.

Se assumirmos, com Rosenfeld e Bosi, a pertinência da propriedade verbal augustiana para designar seus conceitos, e se aceitarmos que a referida pertinência se justifica pelos argumentos expostos acima, então poderemos inferir que boa parte das exigências de Schopenhauer quanto à exposição (Darstellung) e à expressividade na arte poética teria sido cumprida. Mesmo que de forma bastante alheia - e até oposta - ao que seria o vocabulário poético schopenhaueriano capaz de apreender a Ideia e transmiti-la intuitiva e objetivamente, como negaríamos que o lirismo de Augusto, ao conduzir a fantasia do ouvinte pelas desventuras da existência, não o faria captar de pronto a natureza asquerosa, pútrida e vencida do mundo? Se o termo técnico e os cientificismos recorrentes e adjetivantes impedissem essa capacidade artística do "poeta maldito", como explicaríamos a expressiva popularidade de seus poemas $^{35}$ e a facilidade com que, no Brasil, os adolescentes se encantam com essa voz da desgraça, memorizando seus versos para toda a vida?

Se uma investigação conceitual pode revelar que as cosmovisões do poeta brasileiro e do filósofo alemão se assemelham em certos sentidos, ou que o "poeta do hediondo" foi influenciado pelo pensador da vontade em termos conceituais

33 Em consonância com o aparato linguístico, que é cientificizado, é preciso considerar também, no plano conceitual, que o fato de o vocábulo científico ser constante e o fato de o poeta citar com frequência os evolucionistas - Haeckel e Spencer - não leva necessariamente à tese de que Augusto dos Anjos era um adepto incondicional do evolucionismo e do positivismo. Ter-se-ia que considerar a semântica das citações e referências do paraibano a essas concepções científicas que, em muitas passagens, não permitem a afirmação da referida interpretação. Como Bosi observa, "a postura existencial do poeta lembra o inverso do cientismo", em consonância com o importante ensaio de José Paulo Paes, que apresenta a cosmovisão de Augusto como um "evolucionismo às avessas" (Cf. PAES, J. P. Augusto dos Anjos e o evolucionismo às avessas. Novos Estudos CEBRAP, n. 33, 1992, pp. 89-102). 
específicos (o que não pretendi mostrar aqui), independentemente disso temos bons motivos para afirmar que no aspecto formal, da caracterização da arte poética, eles guardam proximidades surpreendentes. Ou, de outro modo, poderíamos dizer também que essa questão formal que uniria o poeta ao filósofo não se separa de uma questão conceitual nuclear da metafísica schopenhaueriana do belo. É que o único poema em que um conceito de Schopenhauer aparece diretamente citado é justamente um daqueles em que o poeta mais demonstra o referido desejo de desencarceramento - da forma humana, do "cárcere linguístico", do "eu" poético e de tudo o que supõe alheamento e corrupção -, liberando-os para o "Nirvana" e para a "imortalidade das Ideias".

\section{Referências bibliográficas}

ANJOS, Augusto dos. Obra completa. Organização, fixação do texto e notas: Alexei Bueno. Rio de Janeiro: Nova Aguilar, 1994.

Eu. São Paulo: Hedra, 2012.

Eu e outras poesias. 42 $2^{\mathrm{a}}$ ed. Rio de Janeiro: Civilização Brasileira, 1998.

BARBOZA, Jair. A metafísica do belo de Arthur Schopenhauer. São Paulo: Humanitas FFLCH/USP, 2001.

CALIXTO, Fabiano. Introdução. In: ANJOS, Augusto dos. Eu. São Paulo: Hedra, 2012.

CAVALCANTI, Cláudia. Em busca do êxtase. In: Poesia expressionista alemã: uma antologia. Organização e tradução: Claudia Cavalcanti. São Paulo: Estação Liberdade, 2000. p. 17-33.

DUARTE NETO, Henrique. As cosmovisões pessimistas de Schopenhauer e Augusto dos Anjos. Dissertação de Mestrado. Programa de Pós-Graduação em Literatura. Universidade Federal de Santa Catarina, 2000.

FARIA, José Escobar. A poesia científica de Augusto dos Anjos. In: ANJOS, Augusto dos. Obra completa. Organização, fixação do texto e notas: Alexei Bueno. Rio de Janeiro: Nova Aguilar, 1994. p. 141-149.

FREYRE, Gilberto. Nota sobre Augusto dos Anjos. In: ANJOS, Augusto. Obra completa. Organização, fixação do texto e notas: Alexei Bueno. Rio de Janeiro: Nova Aguilar, 1994. p. 76-81.

MAGALHÃES JúNIOR, Raimundo. Poesia e vida de Augusto dos Anjos. 2. ed. Rio de Janeiro: Civilização Brasileira; Brasília: INL, 1978.

MOISÉS, Massaud. Dicionário de termos literários. 12ª ed. São Paulo: Cultrix, 2004.

PAES, José Paulo. Augusto dos Anjos e o evolucionismo às avessas. Novos Estudos CEBRAP, n. 33, 1992, pp. 89-102.

PRADO, Antonio Arnoni. Um fantasma na noite dos vencidos. In: ANJOS, Augusto dos. Eu e outras poesias. São Paulo: Martins Fontes, 2000.

ROSENFELD, Anatol. Texto/Contexto I. 5a ed. São Paulo: Perspectiva, 2013.

SCHOPENHAUER, Arthur. O mundo como vontade e como representação. Tomo I. $2^{\underline{a}}$ ed. Trad. Jair Barboza. São Paulo: UNESP, 2015.

Metafísica do Belo. Trad. Jair Barboza. São Paulo: UNESP, 2003. 
SHEPPARD, Richard. A poesia expressionista alemã. In: BRADBURY, Malcolm; McFARLANE, James (Org.). Modernismo: guia geral 1890-1930. Tradução: Denise Bottmann. São Paulo: Companhia das Letras, 1999, p. 313-320.

SOARES, Órris. Elogio de Augusto dos Anjos. In: ANJOS, Augusto dos. Eu e outras poesias. 3. ed. Rio de Janeiro: Castilho, 1928. p. VII-XXXVI.

Recebido: $20 / 11 / 15$

Received: 11/20/15

Aprovado: $10 / 12 / 15$

Approved: 12/10/15 